\title{
Drug companies should target drug plans, rather than physicians, consultant says
}

Published at www.cmaj.ca on Nov. 4

$\mathrm{P}$ harmaceutical companies should increasingly focus their attention on payers, such as public and private drug plans, rather than physicians, says Paul Crotty, general manager of IMS Health Canada Ltd.

"What amazes me is the lack of connection between Big Pharma and the payers," Crotty told the seventh annual Canadian meeting of the Drug Information Association in Ottawa, Ontario on Nov. 3.

"Over time, the role of the doctor in deciding what prescriptions get written has eroded," said Crotty, head of the Canadian branch of a global consulting company that provides market research and intelligence to the pharmaceutical and health care industries.

The role played by government drug plans, pharmaceutical approval groups and private drug plans has steadily grown, yet, to date, there has been a "lack of productive conversations" between drug companies and those parties, Crotty added.

But there's a need for a greater alignment between payers and pharmaceutical firms, said Bob Nakagawa, assistant deputy minister of pharmaceutical services for British Columbia.

The current system is inefficient and wasteful, Nakagawa said. "We have products that cost $\$ 800$ million to develop and yet may not be attractive to payers. ... We do not want to spend $\$ 800$ million on a drug that is not needed."

Nakagawa argued that payers and pharmaceutical companies should collaborate to ensure medications that are developed have "real social and medical value." He noted that Canada has experienced a "scary, exponential increase" in prescription drug expenses, from about $\$ 5$ billion in 1980 to more than $\$ 15$ billion this year.

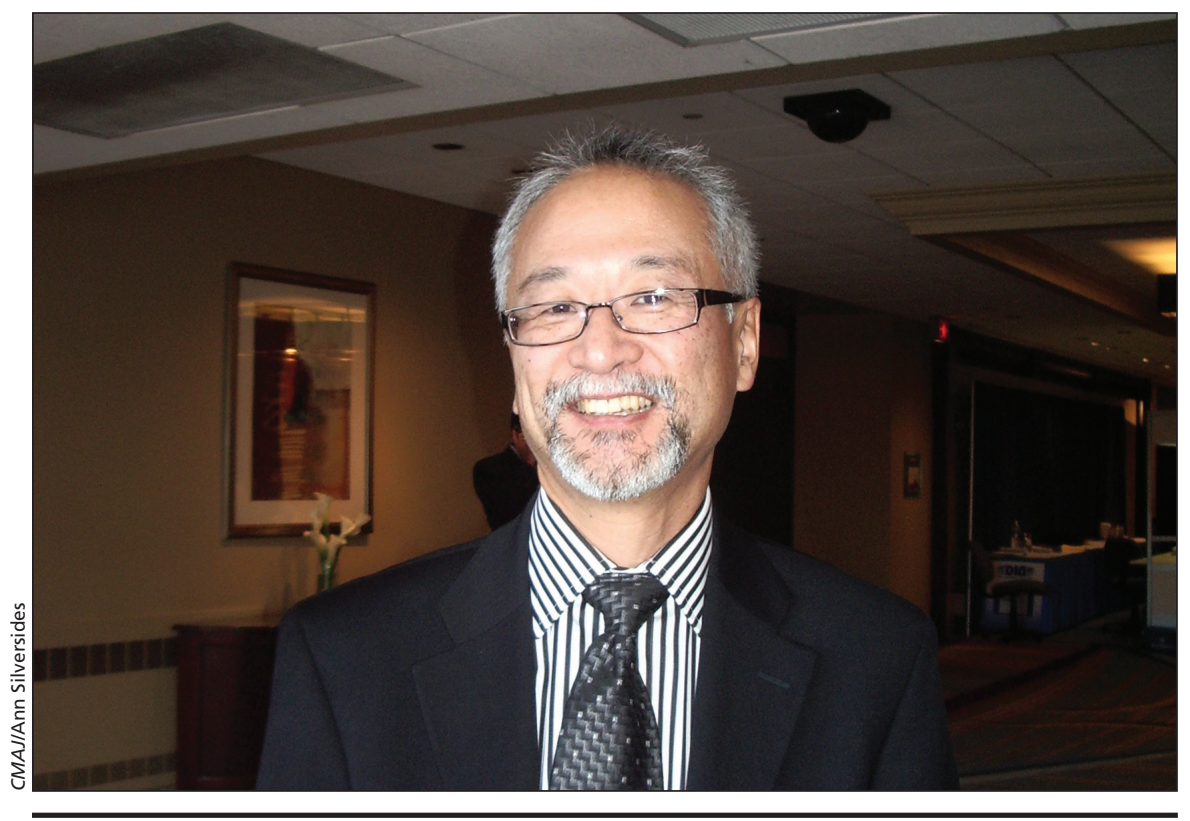

The current pharmaceutical purchasing system is inefficient and wasteful, says Bob Nakagawa, assistant deputy minister of pharmaceutical services for British Columbia.

Payers like the $\mathrm{BC}$ government "want to see innovative products for significant health care gaps," he said. "We are more and more squeezed to live within the allocation government provides us. ... We want a return on investment in terms of health outcomes and a sustainable model."

Drug plans face an enormous challenge in handling the cost of biologics, which often carry annual price tags on the order of $\$ 15000$ to $\$ 25000$ per patient, Nakagawa added. This is "a huge change in the price paradigm" for drug plans, he said, noting that BC's pharmacare program has experienced an average annual cost increase for biologics of $34 \%$ over each of the past four years.

Nakagawa also argued that the pricing of pharmaceutical products should be "commensurate to the level of clinical data support" and that "me-too" drugs that offer no particular advantage over existing pharmaceuticals should be priced at a discount.
Increasingly, payers are moving to "coverage with evidence development," so that if a drug appears to perform well in clinical trials but lacks real-world safety and effectiveness data, they can provide "conditional coverage" while data is being collected, Nakagawa added.

Because some payers are funding drugs on a pay-for-performance basis, if there is no positive therapeutic outcome, the company refunds the drug price, he noted. Such arrangements are typically confidential, but Johnson \& Johnson went public with a 2007 arrangement it made with the United Kingdom's National Health Service under which the latter agreed to pay for bortezomib, a treatment of multiple myeloma, if a patient responded well. The company agreed to refund the drug's costs if a patient showed minimal or no response. - Ann Silversides, CMAJ

DOI:10.1503/cmaj.109-310 


\section{Pharma industry warned that huge profits in the face of the recession are no reason for complacency}

$\mathrm{T}$

he Canadian pharmaceutical market has redefined resilience by growing $7 \%$ during the economic recession, slightly higher than the global average of $6 \%$, according to Paul Crotty, general manager of IMS Health Canada Ltd.

There's a danger, though, that "pharma will think it is in great shape and doesn't have to change," Crotty told more than 250 delegates to the seventh annual Canadian Drug Information Association conference in Ottawa, Ontario. "This would be a significant error."

The industry faces huge challenges, Crotty said. Many top-selling drugs, such as atorvastatin calcium (Lipitor), are coming off patent in the next four years. The industry stands to lose about $\$ 136$ billion of its $\$ 800$-billion global market because of this "patent cliff," he said.

In Canada, the patented market accounts for about $\$ 18$ billion in sales, and $\$ 6.6$ billion of that represents drugs that will go off patent by 2013, Crotty added.

As well, of the 30 new pharmaceutical entities launched globally this year, only five have the potential to be blockbusters and earn annual revenues in excess of $\$ 1$ billion, he said.

Meanwhile, 2007 amendments to the Food and Drug Act will make the United States Food and Drug Administration (FDA) "significantly more risk-averse," Crotty said. The agency's attitude toward pharmaceutical safety and evidence has become: "If you can know it, you should know it." With higher levels of proof required, the result will be longer, larger and more expensive clinical trials, he added, noting that the FDA has demanded risk and mitigation strategies for four of the 18 approvals it has granted to date for new clinical entities this year.

Crotty also pointed to several other trends that will affect the industry:

- South Korea, which had given its population unlimited access to pharmaceuticals - 13000 products were available, compared to about 8500 in the United States — has introduced health technology assessment (scientific evaluation of the clinical and cost-effectiveness of health products like drugs) to bring down costs. The approach "will be picked up by other markets in southeast Asia."

- Several pharmaceutical companies have restructured their research and development units to become smaller and "more entrepreneurial." Some firms are moving out of some sectors, as was the case when Pfizer Inc. withdrew from the cardiovascular market. 